\title{
Ecobatimetria aplicada ao estudo da hidrovia do Rio Madeira
}

Arthur N. D. V. Pinheiro (arthur@petcon.com.br - PETCON), lanniruberto, M. (ianniruberto@unb.br - IG/UnB), Érick Luiz (erick.luiz@petcon.com.br - PETCON), Thiago Lott (thiago.lott@petcon.com.br - PETCON)

Copyright 2014, SBGf - Sociedade Brasileira de Geofísica

Este texto foi preparado para a apresentação no VI Simpósio Brasileiro de Geofísica, Porto Alegre, 14 a 16 de outubro de 2014. Seu conteúdo foi revisado pelo Comité Técnico do VI SimBGf, mas não necessariamente representa a opinião da SBGf ou de seus associados. É proibida a reprodução total ou parcial deste material para propósitos comerciais sem prévia autorização da SBGf.

\section{Abstract}

The valorization of the waterway transportation can leed to a regional economic development in many regions of Brazil, such as the North region. The Madeira's waterway constitutes a shipment trasnportation net that potentizes the spacial articulation and the materials flow activation. The application of the singlebeam bathymetry allowed the definition of the navigable channel trace of the Madeira's waterway between Porto Velho (RO) and it's mouth, in the Amazonas river, the critical points, and the volumes of material that must be removed to ensure the complete navigation in the waterway.

\section{Introdução}

O Brasil possui uma das maiores redes fluviais do mundo, com capacidade para a implantação de um sistema hidroviário bastante vantajoso, considerado como o modal mais barato e eficiente na movimentação de granéis ou grandes cargas em geral (OLIVEIRA, 2010).

A valorização do transporte hidroviário pode levar a uma reestruturação da economia e um desenvolvimento econômico e regional em diversas áreas do país, como por exemplo, a região Norte que possui excepcional potencial hidroviário, e apresenta a navegação interior como um dos principais meios de transporte de cargas e passageiros.

O rio Madeira (Figura 1) abrange aproximadamente 1086 quilômetros de navegabilidade em seu estado natural, compreendidos entre Porto Velho (RO) e sua foz no rio Amazonas, é classificado como rio de planície de leito arenoso, ou seja, seu leito está em constante mudança ao longo do ano, devido às variações de níveis hidráulicos e dinâmica hídrica. Segundo estudo hidrológico realizado a variação do nível das águas atinge, em média, 14 a 15 metros ao longo do ano.

A hidrovia do Madeira com o auxílio da intermodalidade, forma uma rede de transporte de cargas que potencializa a articulação espacial e a ativação dos fluxos de materiais. Juntamente com o deslocamento da fronteira agrícola no país vem o crescimento de importância da hidrovia, na medida em que aumenta a movimentação entre os portos de Porto Velho (RO) e Itacoatiara (AM) com produtos destinados à exportação. A busca por uma matriz de transportes mais equilibrada e pela redução dos custos rodoviários que tanto oneram os produtos brasileiros, resulta no escoamento da carga oriunda da região Centro-oeste brasileira por esta hidrovia. Como carga de retorno, observa-se que fertilizantes importados e cimentos são os principais produtos transportados.

A tabela abaixo apresenta os Quilos de poluentes produzidos no transporte de 1 tonelada de carga na distância de 1.609,34 Km (1.000 milhas), percebe-se que o uso de hidrovias reduz consideravelmente a emissão de poluentes

Tabela 1: Comparativo entre as emissões de gases poluentes de cada meio de transporte. Fonte: Agência de Proteção Ambiental - Lab. De Controle de Emissão EUA.

\begin{tabular}{|l|l|l|l|}
\hline Modo & Hidrocarbonetos & $\begin{array}{l}\text { Monóxido } \\
\text { de } \\
\text { Carbono }\end{array}$ & $\begin{array}{l}\text { Oxido } \\
\text { nitroso }\end{array}$ \\
\hline $\begin{array}{l}\text { Empurrador } \\
\text { (hidrovia) }\end{array}$ & $0,041 \mathrm{~kg}$ & $0,091 \mathrm{~kg}$ & $\begin{array}{l}0,240 \\
\mathrm{~kg}\end{array}$ \\
\hline Trem & $0,21 \mathrm{~kg}$ & $0,29 \mathrm{~kg}$ & $0,83 \mathrm{~kg}$ \\
\hline Caminhão & $0,286 \mathrm{~kg}$ & $0,862 \mathrm{~kg}$ & $\begin{array}{l}4,613 \\
\mathrm{~kg}\end{array}$ \\
\hline
\end{tabular}

A batimetria é uma das principais ferramentas para realização de estudos preliminares e acompanhamento de obras para viabilização de novas hidrovias, e manutenção de hidrovias já consolidadas.

A partir da batimetria monofeixe, e com a ajuda de práticos locais, definiu-se o traçado do canal navegável da hidrovia do Madeira, entre Porto Velho e sua Foz; os pontos críticos, ou seja, trechos que oferecem perigos à navegação, seja pela profundidade ou pela presença de rochas aflorantes; e os volumes de material a ser retirados para garantir a navegabilidade completa na hidrovia. 


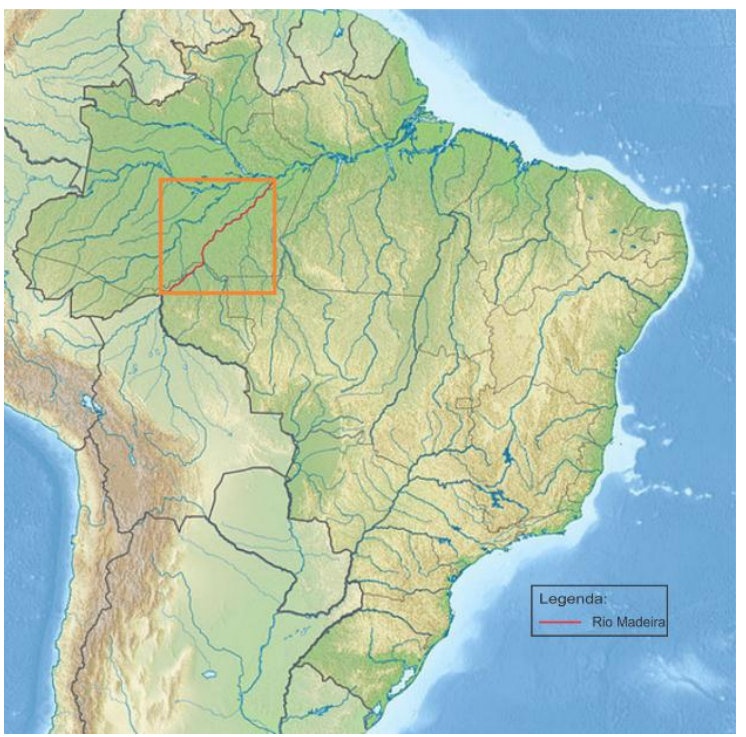

Figura 1: Figura ilustrativa com a localização do rio Madeira.

\section{Metodologia}

Inicialmente, desenvolve-se uma série de estudos aprofundados com relação à carga transportada, a demanda de transporte, as embarcações já utilizadas na hidrovia, as vantagens econômicas e ambientas da utilização da hidrovia, e a partir destes estudos define-se o comboio-tipo (Figura 2). Esta é a embarcação que apresenta a melhor viabilidade técnica, operacional, econômica e ambiental a ser utilizada, para fins de projeto. A partir das dimensões deste comboio-tipo, e das publicações da "Permanent International Association of Navigation Congresses" (PIANC), "Arquiteture Navale Analyse dês Systèmes de Transport" (ANAST), e "United States Army Corps of Engineers" (USACE), determinouse a geometria do canal navegável, apresentada a seguir.

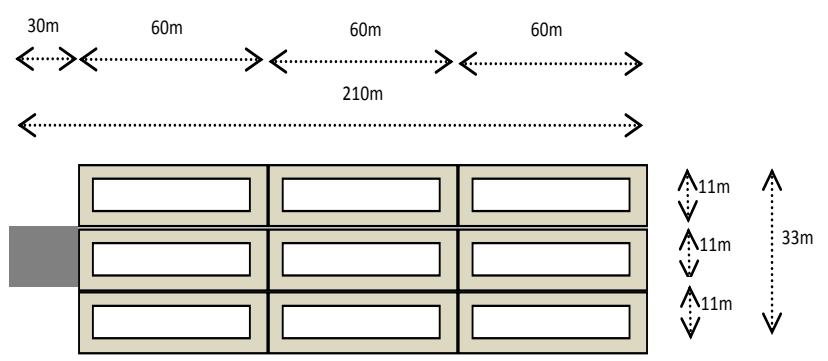

Figura 2: Comboio-tipo proposto para a Hidrovia do Madeira (9 Balsas graneleiras + Empurrador).
Tabela 2: Geometria de canal proposta para a Hidrovia.

\begin{tabular}{|c|c|}
\hline Largura da base & $75 \mathrm{~m}$ \\
\hline $\begin{array}{l}\text { Comprimento } \\
\text { comboio-tipo (L) }\end{array}$ & $210,00 \mathrm{~m}$ \\
\hline $\begin{array}{l}\text { Raio de curvatura sem } \\
\text { sobrelargura (R) }\end{array}$ & $R>2100 m$ \\
\hline Sobrelargura & $\begin{array}{c}\mathrm{L}^{2} /(2 \times \mathrm{R}), \text { se } 4 \times \mathrm{L}<\mathrm{R}< \\
10 \times \mathrm{L}\end{array}$ \\
\hline Profundidade & $\begin{array}{c}\text { 3,00 m (base do canal) + } \\
0,50 \mathrm{~m} \text { (pé-de-piloto). }\end{array}$ \\
\hline $\begin{array}{l}\text { Talude do canal leito } \\
\text { arenoso }\end{array}$ & $1: 8(\mathrm{~V}: \mathrm{H})$ \\
\hline $\begin{array}{l}\text { Talude do canal leito } \\
\text { rochoso }\end{array}$ & $1: 1(\mathrm{~V}: \mathrm{H})$ \\
\hline
\end{tabular}

Concomitantemente a essa fase inicial, realiza-se o estudo hidrológico da Hidrovia, ou seja, a análise histórica do nível (cota) da lâmina d'água registrado nos postos limnimétricos ao longo de toda a hidrovia, para determinação das médias mínimas em cada posto. Etapa de suma importância, pois são os valores que utilizar-seá para reduzir dos dados o nível d'água observado no momento dos levantamentos a altura mínima média do nível d'água, definida no estudo hidrológico, para época de águas baixas, ou seja, simular a situação que, estatisticamente, é mais provável de ocorrer anualmente.

Superada a fase de estudos iniciam-se os trabalhos de campo de batimetria. O sistema de posicionamento adotado nos levantamentos foi o sistema DGPS submétrico, nominal, de base virtual, OmniStar, com recepção da correção diferencial via satélite de comunicações. O Datum adotado foi o WGS-84, tendo-se utilizado, na navegação em tempo real para coleta e igualmente no processamento dos dados, as coordenadas puras coletadas pelo DGPS. Utilizou-se os batímetros Echotrac CVM e Echotrac CV100, Teledyne Odom Hidrographic, e o software Hypack, Hypack Inc., para aquisição e processamento dos dados, o qual registra os dados do Ecobatímetro e do DGPS, fornecendo a profundidade georreferenciada do ponto verticalmente abaixo do transdutor.

O levantamento batimétrico foi dividido em duas etapas, levantamento longitudinal para reconhecimento e determinação dos pontos críticos, e o levantamento detalhado destes pontos críticos.

Para realização do levantamento longitudinal instalou-se dois sistemas de aquisição independentes (Figura 3) em lados opostos do barco, espaçados de aproximadamente 6 metros. Ambos os batímetros trabalharam na faixa de $200 \mathrm{kHz}$ conectados a um único DGPS com duas saídas serial NMEA localizado no teto do Barco. 
A utilização de dois Ecobatímetros com mesma frequência $(200 \mathrm{kHz})$ distantes de aproximadamente 6 metros, gerou problemas com interferência e múltiplas, contornados com a simples modificação da frequência para $195 \mathrm{kHz}$ em um batímetro e $205 \mathrm{kHz}$ no outro.

As profundidades foram registradas continuamente enquanto a embarcação se deslocava ao longo do canal navegável do rio Madeira, desde a sua Foz até Porto Velho (RO).

Definidos os pontos críticos realizou-se os levantamentos detalhados de alta resolução, com linhas planejadas transversalmente ao curso do rio de margem à margem, espaçadas em 20 metros para leito arenoso e 5 metros no caso de rochas aflorantes para determinação da posição do canal navegável no trecho e das obras de manutenção que deverão ser realizadas para adequá-lo à geometria de canal proposto no projeto.

A etapa final é o cálculo de volume de material a ser retirado em cada trecho onde se faz necessária intervenção para garantir a navegabilidade segura. Os cálculos de volumes são realizados no próprio software Hypack, a partir da sobreposição do TIN MODEL do leito mapeado e do canal navegável proposto para o trecho (3D), com ambos os dados sobrepostos o software calcula o volume de material que encontra-se no interior do canal. Para efeitos de cálculo o canal é divido em seções transversais (cross-sections) espaçadas simetricamente, 20 metros para leito arenoso e 5 metros para leito rochoso (Figura 4), com isso o volume de material é individualizado por seção, para auxiliar na logística de execução das obras de adequação.

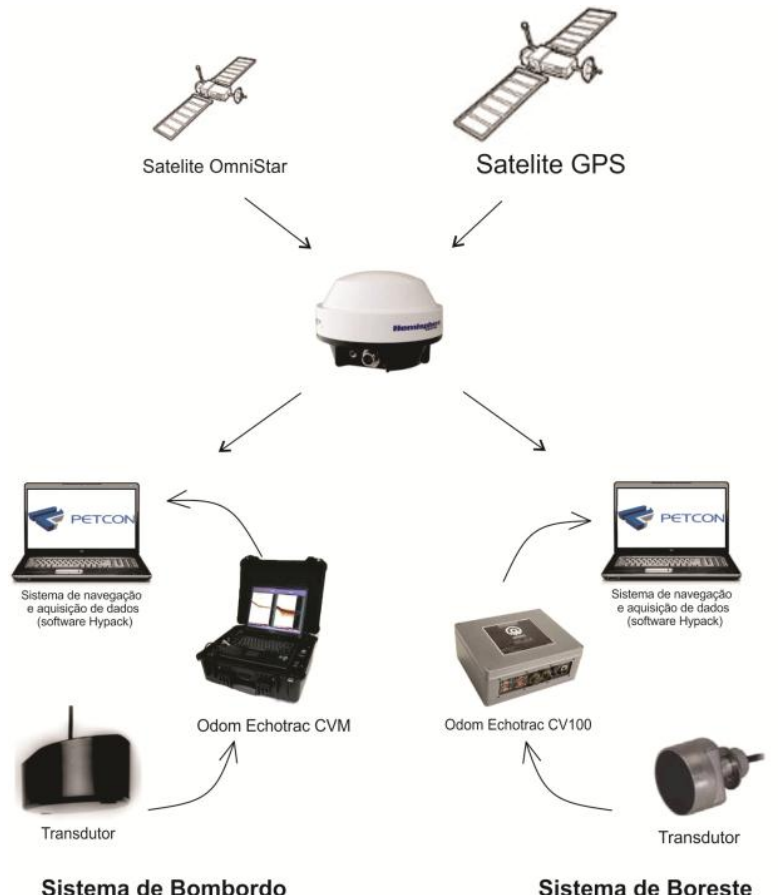

Sistema de Boreste
Figura 3: Sistemas de aquisição de dados utilizados no levantamento longitudinal.

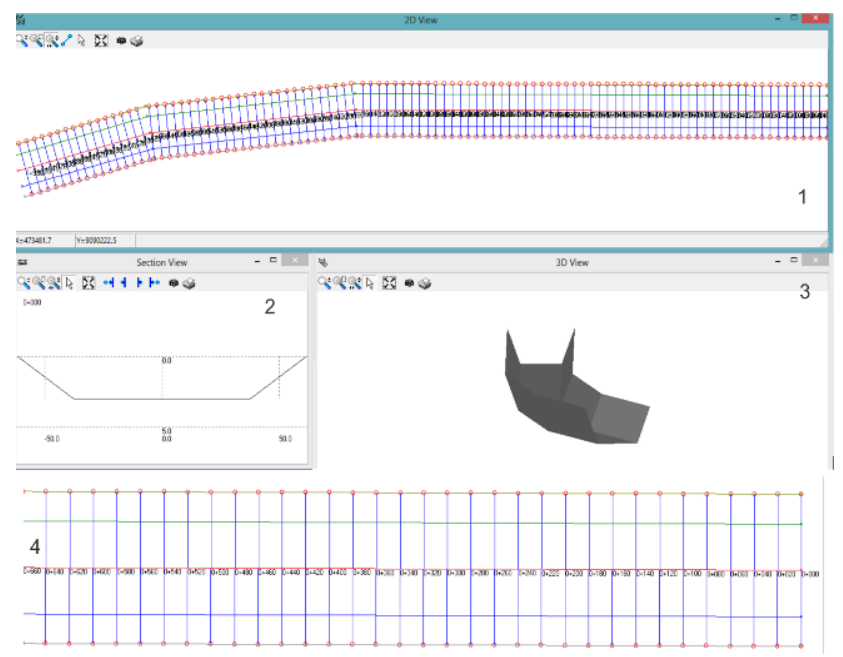

Figura 4: Geometria do canal proposta para trechos de leito arenoso. (1) visualização em planta do canal proposto para o trecho divido em seções transversais para o cálculo de volume, (2) visualização em corte do canal, (3) visualização 3D do canal, (4) visualização em detalhe do estaqueamento plotado em (1).

\section{Resultados}

A primeira campanha batimétrica possibilitou a geração do perfil batimétrico longitudinal da Hidrovia, desde a sua Foz até Porto Velho. Analisando o perfil define-se os pontos críticos que apresentam profundidades menores que 3 metros (Figura 5). Este perfil longitudinal servirá de base para determinação do traçado do canal navegável e da quilometragem da hidrovia, neste caso medida de jusante para montante.

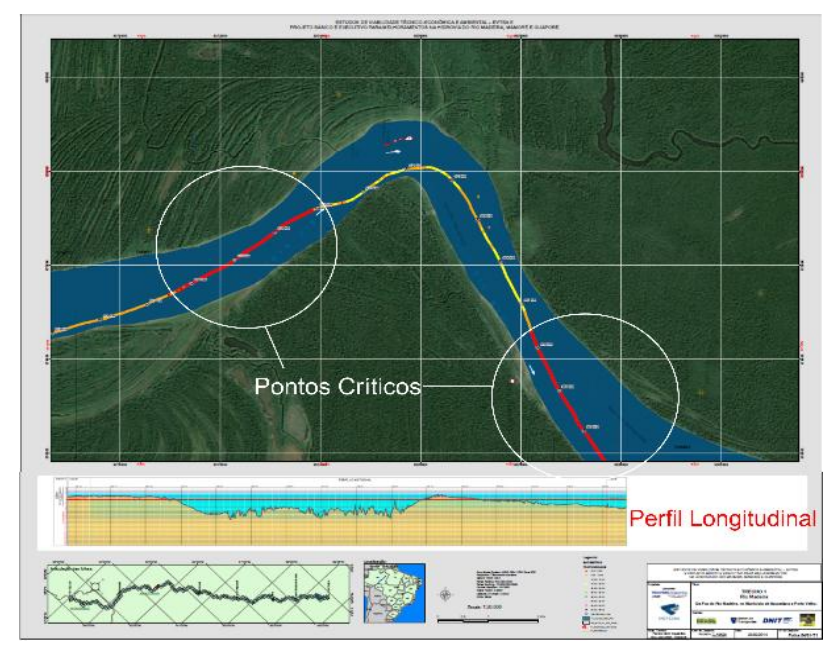

Figura 5: Mapa batimétrico com perfil longitudinal do rio Madeira 
A partir dos levantamentos detalhados dos pontos críticos foram desenvolvidas as plantas batimétricas dos mesmos (Figura 6), estas apresentam a malha batimétrica, o traçado do canal, definido a partir da análise da malha batimétrica e dos modelos 3D, juntamente com a posição das seções transversais (cálculo de volume), e a sinalização flutuante proposta para o trecho, quando necessária.

Modelos 3D completos dos pontos críticos, com canal navegável e balizamento flutuante auxiliam a visualização de como ficará 0 trecho em questão após as intervenções. A análise destes modelos ajuda na determinação do posicionamento do canal, pois fornecem uma visualização mais dinâmica do trecho em questão. Observa-se nos modelos do Capitari (Figura 7) a necessidade de estreitar-se o canal, passando de 75 metros de base para 60 metros, este fato ocorre devido à complexidade técnica e ambiental na execução de derrocamento e da inviabilidade ambiental de realizar-se supressão de margem. Apesar de apresentar pequeno volume de dragagem, os pedrais do Capitari são obstáculos extremamente perigosos à navegação e o balizamento flutuante é fundamental para a navegação segura de embarcações no trecho. Os modelos 3D do trecho denominado Pombal (Figura 8) auxiliam na determinação da localização dos pedrais que trazem perigos à navegação. Este ponto crítico já apresenta volumes um pouco maiores de dragagem, mas localizados em um pequeno trecho do canal navegável. Em Abelhas (Figura 9) verifica-se o maior volume de material a ser retirado, observa-se, também, a presença de pedrais volumosos que apresentam elevado risco à navegação.

Seguidamente, realizou-se os cálculos de volume de material a ser retirado (Figura 10), o software apresenta os cálculos individualizados por seção, com imagem da mesma juntamente com relatório individual, o qual consta área de material a ser retirado na seção, volume de material entre as seções, e o volume e área acumulados até então. O Capitari apresenta necessidade de pequena intervenção com volume de apenas $6,291.17 \mathrm{~m}^{3}$. Pombal apresenta volume um pouco maior igual a $28,995.12 \mathrm{~m}^{3}$, mas trecho a ser dragado com apenas 230 metros de extensão. Já o ponto crítico Abelhas apresenta elevado volume de dragagem igual a $145,438.08 \mathrm{~m}^{3}$, pelo fato de haver a necessidade de desviar-se dos pedrais, e com isso o canal navegável atravessa local de forte assoreamento.

\section{Discussão e Conclusões}

A batimetria é uma das principais ferramentas não só em estudos preliminares para determinação da viabilidade, e orçamentos de custos de manutenção, como também para acompanhamento, fiscalização das obras, e até mesmo para realização do cálculo de volume de material retirado, ou seja, cálculo do valor a ser pago pelos serviços prestados.

Se a utilização de métodos de imageamento de fundo possibilitam a definição das propriedades dos horizontes sedimentares e rochosos pelo contraste de impedância acústica entre as rochas aflorantes e o leito arenoso, os modelos batimétricos 3D podem em parte suprir nesta tarefa pois os pedrais podem ser identificados pelas feições morfológicas peculiares, como o gradiente batimétrico abrupto.

Apesar dos altos valores de manutenção exigidos anualmente para hidrovias de fundo móvel, devido ao elevado transporte de sedimentos (assoreamento), como no caso da Hidrovia do Madeira, a utilização do meio hidroviário resulta na diminuição dos custos de transporte de cargas e passageiros e menor impacto ambiental, possibilitando melhor competitividade dos produtos brasileiros no mercado internacional, bem como a redução nos dividendos de manutenção de rodovias, e na emissão de gases poluentes.

Desta forma os custos de manutenção da hidrovia ficam justificados pelas vantagens diretas e indiretas geradas.

\section{Referências}

OLIVEIRA, L. R. R. (2010). Geomorfologia Fluvial e navegabilidade do baixo curso do rio Tocantins. Instituto de Geociências, Universidade de Brasília, Brasília, DF, $106 p$.

PIANC - Permanent International Association of Navigation Congresses.

ANAST - Arquiteture Navale Analyse dês Systèmes de Transport.

USACE - United States Army Corps of Engineers.

Souza, Luiz Antonio Pereira de. Revisão crítica da aplicabilidade dos métodos geofísicos na investigação de áreas submersas rasas. / Luiz Antonio Pereira de Souza. São Paulo, 2006. 311p.

Alfredini, P.; Arasaki, E. Obras e Gestão de Portos e Costas: A Técnica Aliada ao Enfoque Logístico e Ambiental. 2 ${ }^{\underline{a}}$ Edição. São Paulo. Editora Blucher, 2009. 804 p.

REYNOLDS, J. M. Na introduction to applied and environmental geophysics. Jhon Wiley \& Sons Inc. 796 p. 1997. 


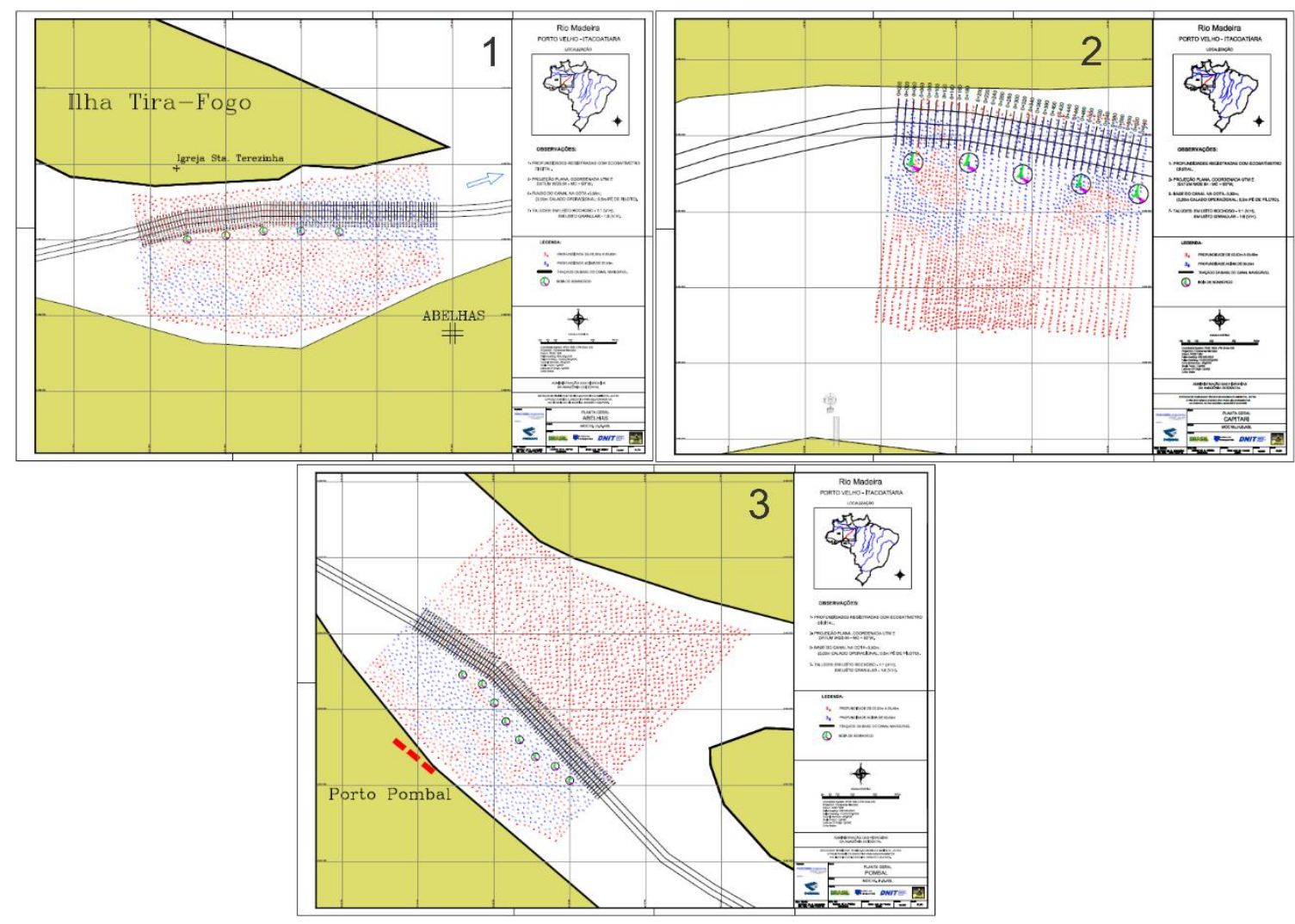

Figura 6: Plantas Batimétricas: (1) Abelhas, (2) Capitari, (3) Pombal.
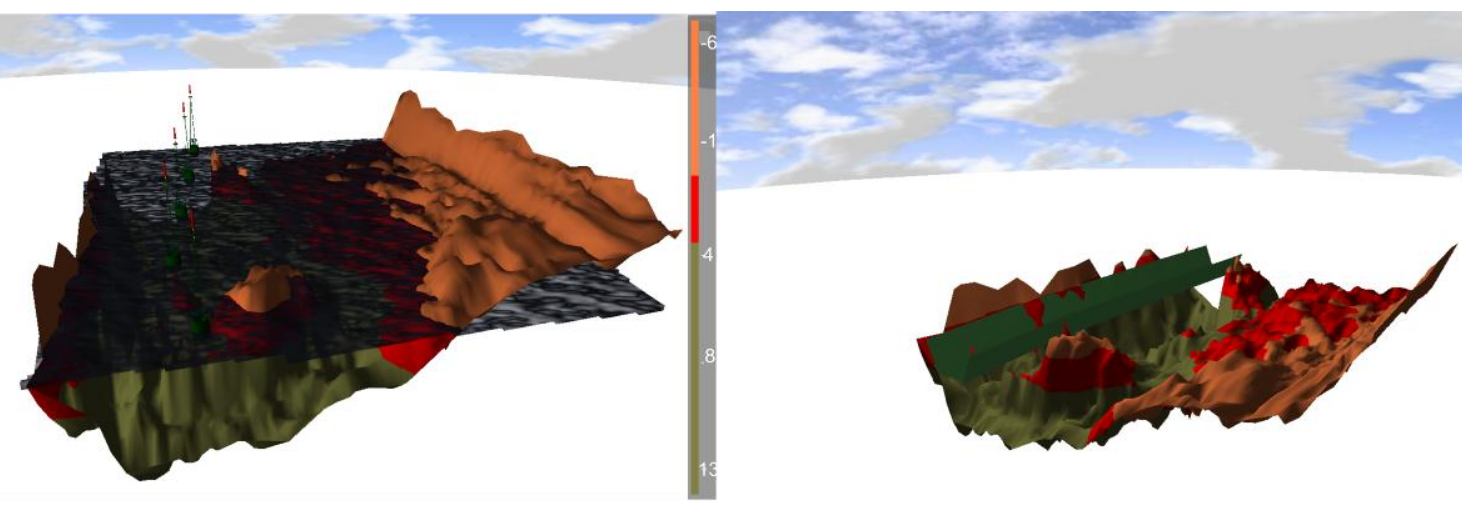

Figura 7: Modelos 3D do ponto crítico Capitari. 


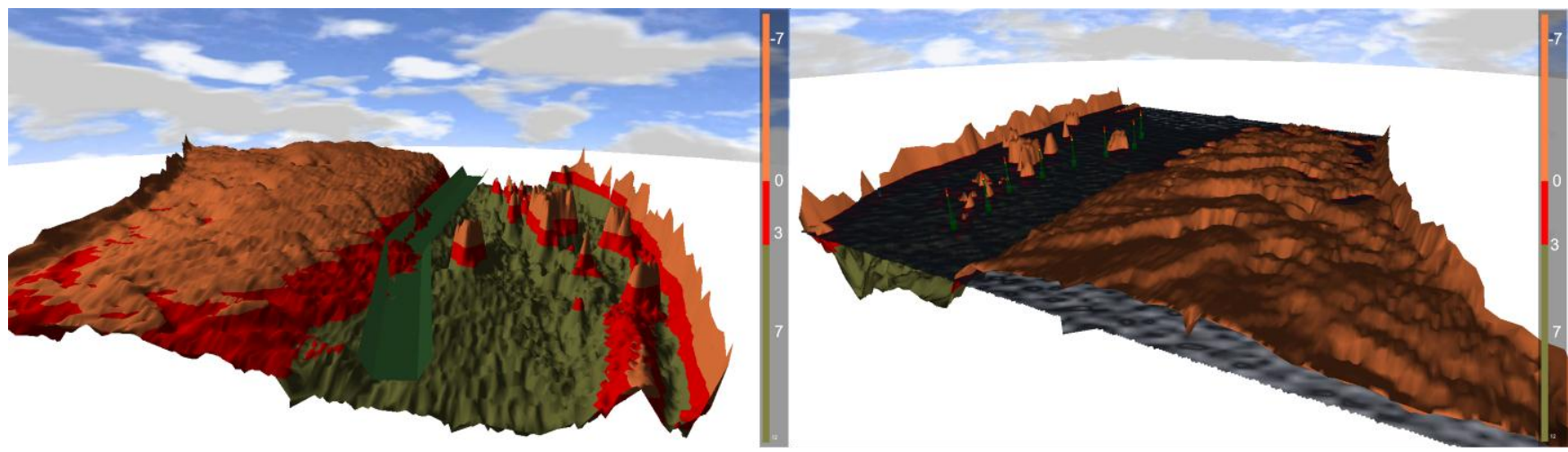

Figura 8: Modelos 3D do ponto crítico Pombal.
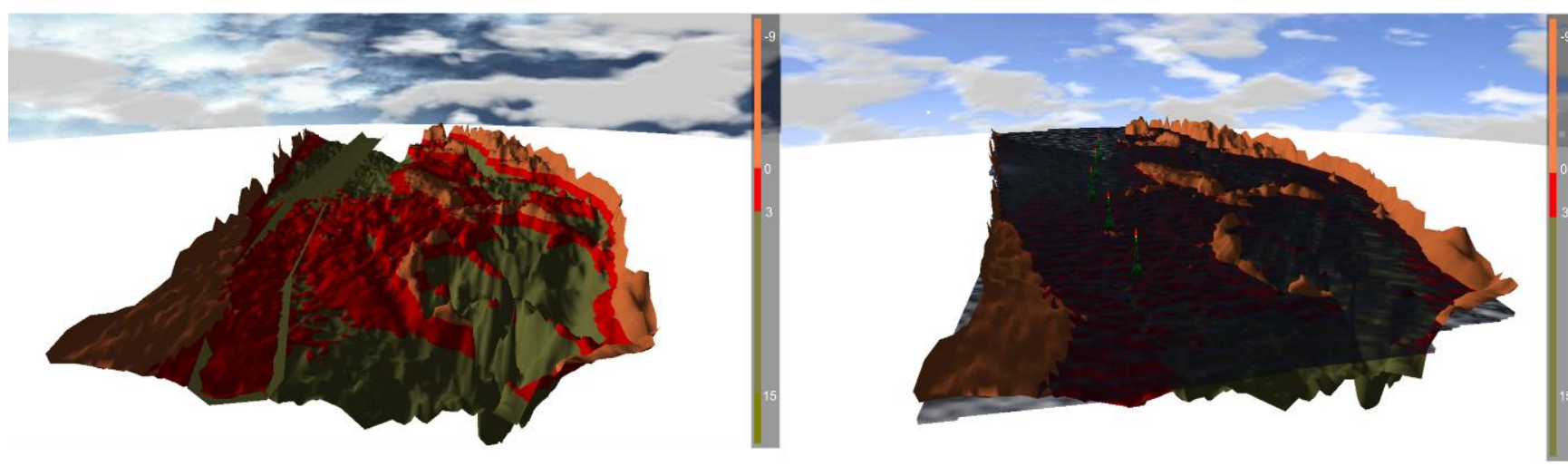

Figura 9: Modelos 3D do ponto crítico Abelhas.

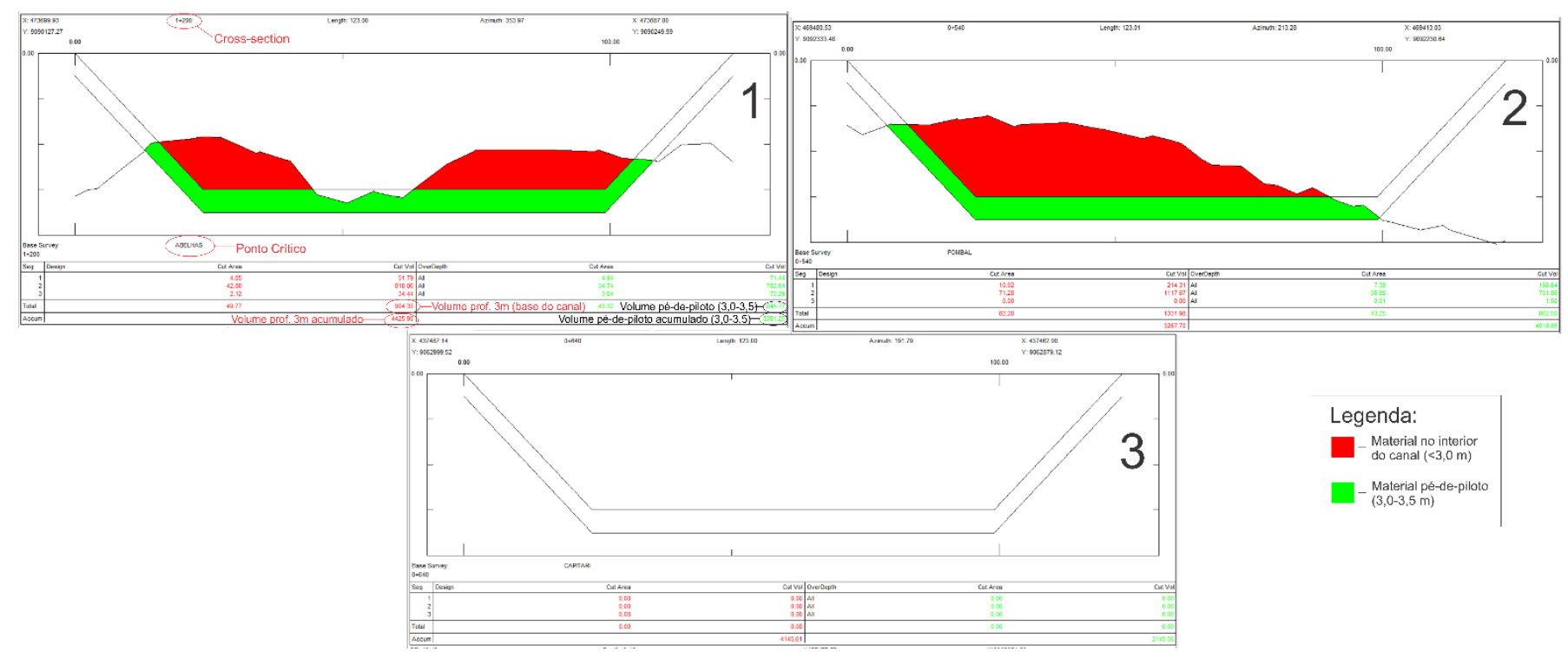

Figura 10: Exemplos de seções-transversais (cross-section) do cálculo de volume. (1) Abelhas, (2) Pombal (3)Capitari 